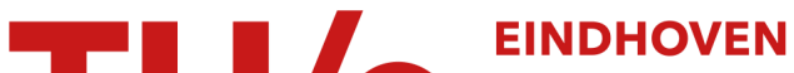 UNIVERSITY OF TECHNOLOGY
}

\section{Power system protection with digital overcurrent relays}

\section{Citation for published version (APA):}

Kiliçkiran, H. C., Șengör, İ., Akdemir, H., Kekezoğlu, B., Erdinç, O., \& Paterakis, N. G. (2018). Power system protection with digital overcurrent relays: a review of non-standard characteristics. Electric Power Systems Research, 164, 89-102. https://doi.org/10.1016/j.epsr.2018.07.008

DOI:

10.1016/j.epsr.2018.07.008

Document status and date:

Published: 01/11/2018

\section{Document Version:}

Accepted manuscript including changes made at the peer-review stage

\section{Please check the document version of this publication:}

- A submitted manuscript is the version of the article upon submission and before peer-review. There can be important differences between the submitted version and the official published version of record. People interested in the research are advised to contact the author for the final version of the publication, or visit the $\mathrm{DOI}$ to the publisher's website.

- The final author version and the galley proof are versions of the publication after peer review.

- The final published version features the final layout of the paper including the volume, issue and page numbers.

Link to publication

\section{General rights}

Copyright and moral rights for the publications made accessible in the public portal are retained by the authors and/or other copyright owners and it is a condition of accessing publications that users recognise and abide by the legal requirements associated with these rights.

- Users may download and print one copy of any publication from the public portal for the purpose of private study or research.

- You may not further distribute the material or use it for any profit-making activity or commercial gain

- You may freely distribute the URL identifying the publication in the public portal.

If the publication is distributed under the terms of Article 25fa of the Dutch Copyright Act, indicated by the "Taverne" license above, please follow below link for the End User Agreement:

www.tue.nl/taverne

Take down policy

If you believe that this document breaches copyright please contact us at:

openaccess@tue.nl

providing details and we will investigate your claim. 


\title{
Power System Protection With Digital Overcurrent Relays: A Review of Non-Standard Characteristics
}

\author{
Hasan Can Kılıçkıran ${ }^{\mathrm{a}, \mathrm{b}, *}$, İbrahim Şengör ${ }^{\mathrm{a}}$, Hüseyin Akdemir ${ }^{\mathrm{a}}$, Bedri Kekezoğlu ${ }^{\mathrm{a}}$, Ozan Erdinça,c, Nikolaos G. \\ Paterakis ${ }^{b}$ \\ ${ }^{a}$ Yildiz Technical University, Department of Electrical Engineering, Davutpasa Campus, Esenler, 34220, Istanbul, Turkey \\ ${ }^{b}$ Eindhoven University of Technology (TU/e), Department of Electrical Engineering, PO Box 513, 5600 MB, Eindhoven, The \\ Netherlands \\ ${ }^{c}$ INESC-ID, Instituto Superior Técnico, University of Lisbon, Lisbon 1049-001, Portugal
}

\begin{abstract}
Power systems are experiencing structural changes induced by the integration of distributed generation units and the operation of microgrids. This transformation has posed new challenges in well-established power system practices and especially on the design and coordination of protection systems. At roughly the same time, technological advancements in protective equipment have constituted the basis for the emergence of digital overcurrent relays which enable alternative approaches to standard protection schemes. As a consequence, recent studies aimed to provide a reliable protection system capable of responding to the modern power system conditions by propounding the utilization of non-standard characteristics (N-SCs), as opposed to the standard characteristics, i.e., characteristics that are not described in the currently used standards. Despite the fact that the effects of the aforementioned changes on the protection of power systems have been thoroughly analyzed in the technical literature, the requirements for devising N-SCs have not been discussed in detail so far. To address this gap, this paper classifies and analyzes the related studies with respect to their potential advantages and disadvantages. Moreover, based on the literature review, recommendations for further research in this area and a list of the requirements for devising robust non-standard relay characteristics are presented.
\end{abstract}

Keywords: digital relay, non-standard characteristic, non-standard curve, protection, unconventional characteristic.

\section{Introduction}

\subsection{Motivation}

The evolution of power systems has accelerated in the recent years. In conventional power systems, planning and operation may be achieved in a central manner because the bulk amount of power is generated by central power plants, and is then transferred to consumers through transmission and distribution system. However, due to several reasons such as the depletion of fossil fuel reserves, growing concerns about the climate change, etc., the conventional power systems have been exposed to the proliferation of distributed generation (DG), which allows power to be generated in small portions and to be injected at various location in power system [1]. In addition to the increasing number of DG connections, the recently introduced concept of microgrids (MGs) brings about extra challenges, especially when considering that power systems are on the eve of islanded MG operation [2].

Apart from the challenges induced by the integration of DG, power systems are likely be exposed to a more dynamic way of operation. The constantly decreasing switching costs of circuit breakers will probably provide an opportunity for more frequent reconfiguration of power systems in the near future [3]. In addition to that, the growing importance of engaging individual consumers in electricity market operations will possibly enforce more

*Yildiz Technical University, Department of Electrical Engineering, Davutpasa Campus, Esenler, 34220, Istanbul, Turkey.

Email address: hckiran@yildiz.edu.tr (Hasan Can Kılıçkıran) 

interaction 4 .

The aforementioned evidence suggest that the power system of the future will be more dynamic compared to the current grid structure. The main features are listed as follows:

- Increased penetration of DG technologies,

- integration of MG with the potential for operating in islanded mode,

- dynamic reconfiguration for operational purposes,

- significant role of electricity market operations.

These features raise concerns as regards the suitability of the existing perceptions of protection, stability, power flow management, etc, which should be evaluated in terms of their ability to reflect and accommodate these features.

One of the primordial challenges faced by power systems due to the changing structure is the protection issue because of the change in load and fault currents. The conventional approach to power system protection which is based on both the calculated load and fault currents, is no longer valid under varying topology. Taking into account that the distribution systems have many branches possibly with different kinds of protective equipment, and also, that distribution systems are prone to structural changes such as integration of DG, MG operation, etc., it may be deduced that the conventional protection systems are likely to malfunction in distribution system applications. As a consequence, questions have been raised about protection systems, especially for distribution systems 5 .

The most common types of protection apparatus used in distribution systems is the overcurrent relay (OCR). An OCR is a device that measures the current which passes through it and determines whether or not to send a signal to open a circuit breaker [6]. There are several types of relays such as distance relays, directional relays, definite time OCRs, etc. However, inverse-time OCR is the most preferable type of protection relay in the distribution systems because of the grading time characteristic that allows some specific loads to draw higher currents for a short period of time [7. As the name implies, the operating time (OT) of the inverse-time OCRs is determined inversely proportional to the fault current seen by relay. There are both digital and electromechanical OCRs. Until two decades earlier, the market was dominated by electromechanical OCRs because they were inexpensive and their performance was well-known as a result of the many years of application. However, digital OCRs are now more likely to replace with the electromechanical OCRs in the following years due to reasons listed below [, 9 :

- Economically competitive: their cost is as low as electromechanical OCRs.

- Increased reliability: they are able to avoid malfunction operation by detecting and reporting internal problems in the relay itself.

- Smart grid natives: their digitalized nature makes them compatible with the smart grid concept.

- Multifunctionality: they are able to perform additional tasks such as measurement voltage and current values along with protection.

The protection of distribution systems was thoroughly achieved by using standard characteristics until recent structural changes. However, standard characteristics (SCs) were designed to protect the conventional power systems in which the power flow is unidirectional, and are therefore prone to threats arising from new concepts such as power systems including DG, MG operation, more dynamic reconfiguration, etc. The main reason that renders SCs obsolete is the bidirectional power flow when DGs are present. Moreover, in the new generation of power systems, significant fault characteristic changes may be observed due to the MG operation. Yet, as a result of inexpensive switching cost, power system operators may want to increase reconfiguration frequency of the system 
in order to decrease power system losses or meet the electricity market demands. These reasons have pushed the researchers to investigate other protection schemes, which are referred to as non-standard characteristics (N-SCs) in the rest of paper, as opposed to the standard ones [10]. As a consequence, considerable amount of effort has been devoted to making protection systems robust against to the aforementioned changes by using N-SCs. Some of the remarkable attempts aimed to tackle the technical issues raised by new generation of distribution systems used N-SCs which are now more likely to realize by the digital relays 11, 12, 13, owing to recent developments. It is quite common to program the digital relays to reflect the same characteristic with their electromechanical counterparts concerning the coordination with non-programmable downstream devices such as fuses or reclosers [14. Nevertheless, this situation might change in the near future due to the evolving distribution systems, especially the ones fully equipped with numerical relays [15].

\subsection{Relevant literature}

Several studies which highlight the recent challenging developments on protection issue have been presented in the literature. The review study presented in [16] investigated fault characteristics of both AC and DC distribution systems. The DG effect on protection along with possible protection techniques as the solution to DG effect were also reported. However, it was not intended to present a review about N-SCs. Manditereza et al. [17] presented an accurate synopsis of DG effects on protection coordination. The study argued that conventional protection systems suffer from DG connection while offering the use of different characteristics instead of standard ones. Nonetheless, the research tended to focus on listing the general solutions rather than on the development of N-SCs. Another comprehensive review which presented the protection coordination techniques both in systems with and without penetration of DG, was carried out in [18. The study covered the protection methods for radial distribution network as well as sub-transmission systems while addressing the arising protection issues when DG units are connected to the system. Nevertheless, giving details about the construction of a new protection characteristic was out of the scope of this paper. Apart from these stuides, several attempts have been made to address the MG protection issue. The general principles of MG protection along with the impact of DG was reviewed in [19] and 20]. Yet, another study addressed the challenges in the coordination between different protective equipment in MGs including DG [21]. Also, methods dealing with the challenges in coordination strategies of MGs were summarized in 22. Last but not least, the fault protection solutions were thoroughly assessed particularly for ungrounded AC MGs in 23] and for uni-grounded AC MGs in 24]. These studies addressed the protection issues caused by MG operation, nevertheless, none of these studies aimed to cover N-SC specifically.

\subsection{Contributions and organization of the paper}

The aforementioned studies provide evidence that there is a growing urgency and interest in the topic of the coordination of protection in distribution systems that are undergoing transformations. The focus of these studies was on capturing the current picture of the protection systems and suggest solutions. However, the utilization of N-SCs as a remedy to these challenges has not received much attention. As a result, there is a gap in the literature regarding the key elements of devising a N-SC which is in the scope of this study. More specifically, the contribution of this study is threefold:

- It summarizes the recent research that is aiming to explore opportunities that have emerged because of the advancement in digital OCRs in conjunction with the development of N-SCs.

- It identifies gaps in the technical literature and proposes future research directions. 


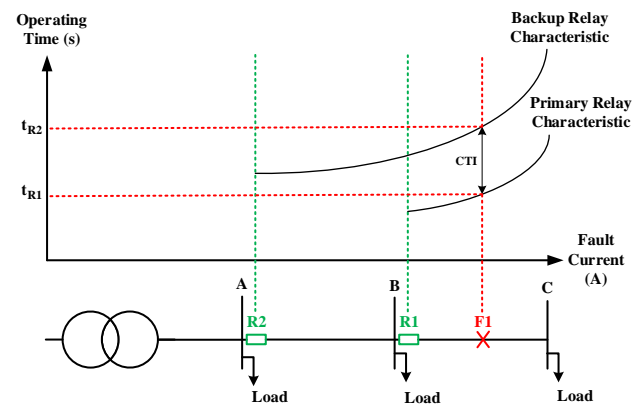

(a)

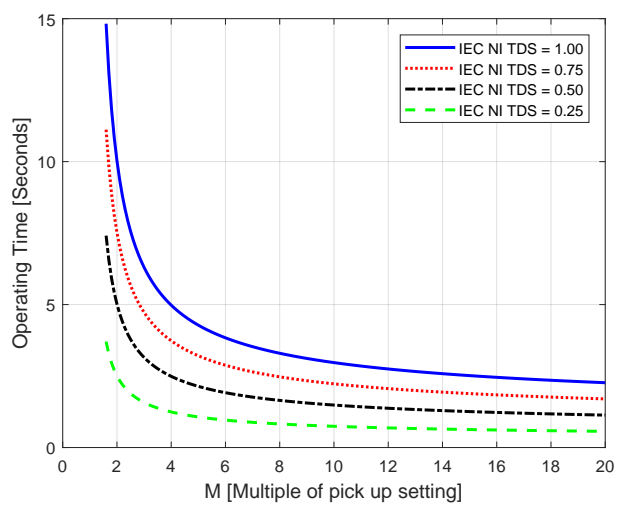

(b)

Figure 1: (a) A simple radial line and curves of protective equipment, (b) Effect of TDS on the IEC NI standard characteristic.

- It complies the basic features that constitute a robust characteristic and should be taken into account by researchers who would like to deal with the protection problem.

The remainder of the paper is organized as follows: Section II provides basic knowledge of conventional protection philosophy while addressing the recent impacts on it. Afterwards, Section III introduces standard relay characteristics published by the IEC and the IEEE. Section IV summarizes the studies which aimed to use N-SCs for power system protection. It is then presented in Section V that the recommendations for future studies. Finally, conclusions and final remarks are presented in Section VI.

\section{Conventional Power System Protection in Distribution Systems and Recent Changes}

Power system protection is defined as detecting abnormal operating conditions in a power system and preventing further threats such as instability or equipment damages, by clearing the faulted part as soon as possible [8]. Thus, the protective equipment should be able to measure the system parameters and distinguish unusual conditions immediately. This feature is defined as sensitivity [25]. Additionally, the protection system is designed to clear faults in such a way that causes the disconnection of the least possible parts of the system, which is referred to selectivity [26]. For example, in Fig. 1a, fault F1 can be cleared either by relay R1 or relay R2. However, the protection system should select R1 in order not to interrupt the load at bus B. In general protection terminology, the term primary refers to the first protective equipment that has to operate in order to clear a fault, while the term backup refers to the second relay that is assigned for the same fault [27]. Besides, the increase in security level of the protection system can be provided by assigning a backup protective equipment for every primary one [28]. By doing so, the protection system can still operate even in case of a primary protective equipment failure. It is also crucial to operate the protection system in harmony. For this reason, the backup protective equipment has to wait for a certain time, which is called coordination time interval (CTI), before taking an action against a fault in its secondary zone. So far, the CTI value is generally chosen in the range of 0.2-0.5 seconds 29 .

The protection scheme of distribution systems is typically composed of various devices such as OCRs, reclosers, fuses, and sectionalizers [30]. Having an inverse time-current characteristic (TCC) makes the OCRs one of the most commonly used protective equipment in distribution systems while allows the coordination with other equipment 31. For the sake of illustration, a simple radial line with two OCRs is depicted in Fig. 1a. In this case, R1 and R2 are assigned as the primary and backup relays against F1, respectively. As seen in Fig. 1a, the inverse TCC curves of relays are coordinated for the downstream faults that can be seen by the relays. In the 
conventional protection philosophy, coordination is achieved by adjusting time dial setting (TDS) and the pickup current setting $\left(I_{p}\right)$ variables that appear in standard equations as it will be explained in Section III [32]. The changes in the characteristic curves due to different TDS values can be seen in Fig. 1b, It should be noted that lower TDS values cause lower OTs, however, at the same time the curve tends to lose its flexibility for lower fault currents. In the recent years, an effort has been devoted to the use of optimization techniques in place of other methods such as analytical methods, graph theory, etc. to coordinate protective devices [33. In other words, relay coordination can be cast as a constrained optimization problem with TDS and $I_{p}$ as optimization variables and having as constraints their range, along with the desired CTI to be ensured between relay pairs 34 .

The conventional protection philosophy is completely built on priorly known current direction and magnitude [35. Considering the effect of DG on power systems, the current magnitude or direction is altered because of the increase in bus short-circuit power due to the DG connection [36. Due to the fact that the exact fault current magnitude is a prerequisite in coordination studies, protection of distribution systems should be re-evaluated in case of DG connections. In addition to that, all the elements of the protection equipment are coordinated based on the assumption that distribution systems are operated in radial mode in which power flows only in one direction [37. Other major impacts of the penetration of DG with respect to protection include blinding, false tripping, nuisance (sympathetic) tripping recloser malfunctions and undesired islanding [38. Consider again the same simple radial line, and assume a DG connected to bus B as illustrated in Fig. 2. In this case, the current seen by R1 during the fault F1 increases while the current seen by R2 does not change or decreases depending on fault type [39], which means that the coordination between relay pairs deteriorates. Moreover, the contribution of a DG unit to a fault current depends stronlgy on its type. There are two commonly used DG types: synchronous based DGs and inverter based DGs, which have fault current contribution levels of 6-7 p.u. [40] and 1.5-2 p.u., respectively [41]. It is noteworthy that more complicated power flow situations that pose threats on protection may be observed in mesh grid operation modes.

Another problem arises when MGs are integrated with the distribution system 42. Generally, various DG types such as combined heat and power, photovoltaics, wind, and energy storage units exist in MGs for supplying energy to local consumers. Moreover, MGs are able to operate both in grid-connected and islanded mode [43. In the latter case, due to the limited available sources, especially when DG units are interfaced via an inverter, a decrease in the fault currents is observed in comparison with the grid-connected mode 44]. Evidently, the protective equipment has to be capable of sensing and reacting to these fault current levels. In addition to that, when a fault occurs at the utility side in the grid-connected mode, the MG should be able to switch to islanded mode without losing healthy DG units that are found inside the island. Similarly, it is expected from the protection systems that in case of inner MG faults only the faulted part should be de-energized in a selective manner 45. Regarding these operationally changes in power systems, classical protection design philosophy should be revised in order to adapt new characteristic of power systems.

\section{Standard Characteristics}

This section is devoted to presenting background information about generally accepted and commonly used standard relay characteristics, i.e., the IEC standard characteristics and the IEEE standard characteristics.

Even though the history of electromechanical relays dates back to the years that power systems emerged, they still act as an active part of protection systems. The emergence of microprocessor (computer) based relays in the 1960s motivated a number of studies which aimed to express relay characteristics in terms of mathematical formulas. 


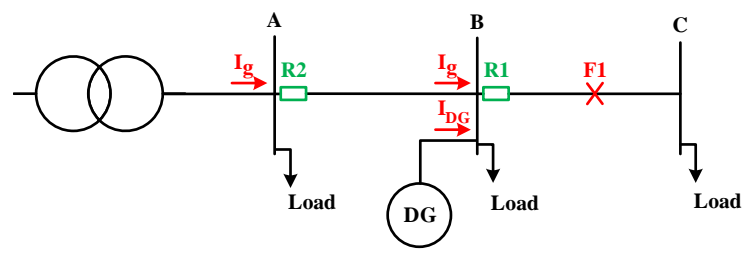

Figure 2: A simple radial line with DG connection.

Table 1: Coefficients Indicated in The IEC 60255-3 Standard 46
\begin{tabular}{|c|c|c|c|}
\hline & Normal Inverse & Very Inverse & Extremely Inverse \\
\hline A & 0.14 & 13.5 & 80 \\
\hline B & 0.02 & 1 & 2 \\
\hline
\end{tabular}

The objective of these studies was to ensure that the protection system operated properly by providing an accurate representation of the relay characteristic in order to coordinate new equipment with their electromechanical ancestors, reclosers and fuses within the protection system. The studies prior to the standards aiming to reflect the operating characteristics of the electromechanical relays were mainly based on the data obtained from the manufacturer or by laboratory experiments. These data were then processed in an analytical way to ensure proper coordination with the aid of equations or graphs. This, in turn, prevented a universal method and led to a customized characteristic depending on the particular protective device. The standards published by the IEC in 1989 [46] and by the IEEE in 1996 [4], established a global approach to reflect the electromechanical relay characteristics using microprocessor based relays by providing SCs.

\subsection{The IEC Standard Characteristic}

As indicated in the IEC 60255-3 Standard [46], the relationship between OT and a characteristic quantity affecting this time may be shown using a characteristic curve. Deciding the shape of this curve may be realized by using either an equation or a graphical method. Although, common practice is more likely to use only the input current value, it was stated in the IEC standard that input current value, input voltage value, DC transient component in an AC magnitude, or etc. may be used as input values in (1). In this equation, the constants $A$ and $B$ are selected from the values given in Table 1 to obtain a normal inverse (NI) characteristic, a very inverse (VI) characteristic, or an extremely inverse (EI) characteristic. The pickup current, $I_{p}$, is a design parameter, while $I_{f}$ denotes the fault current which is sensed by the relay during the fault. Graphical representations of the IEC standard characteristics for different fault current magnitudes are illustrated in Fig. $3 \mathrm{a}$.

$$
t=\frac{A}{\left(\frac{I_{f}}{I_{p}}\right)^{B}-1} \cdot T D S
$$

\subsection{The IEEE Standard Characteristic}

Another widely accepted SC targeting to establish an accurate representation of the output characteristics of electromechanical relays was presented in the IEEE C37.112-1996 Standard 47. The recommended characteristic is given by (2). The point that this characteristic differs from the characteristic specified in the IEC standards is the addition of an extra $C$ parameter. The non-linear relationship between the input current and the flux in the core of the electromechanical relay was the reason for adding an extra parameter. For this reason, the equation of 


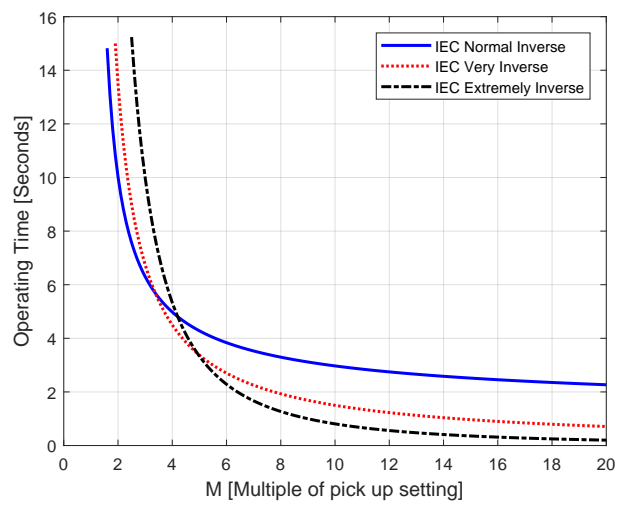

(a)

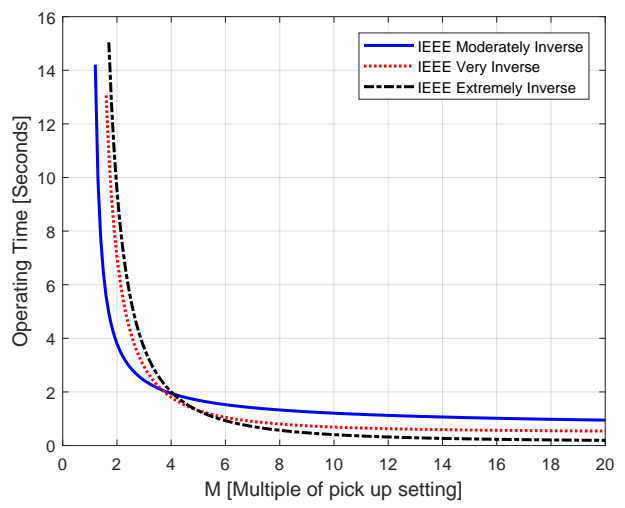

(b)

Figure 3: (a) Inverse time overcurrent relay characteristics determined by the IEC 60255-3 Standard (TDS = 1) 46], (b) Inverse time overcurrent relay characteristics determined by the IEEE C37.112-1996 Standard (TDS =1) [47.

Table 2: Coefficients Indicated in The IEEE C37.112-1996 Standard 47]

\begin{tabular}{|c|c|c|c|}
\hline & Moderately Inverse & Very Inverse & Extremely Inverse \\
\hline A & 0.0515 & 19.61 & 28.2 \\
\hline B & 0.02 & 2 & 2 \\
\hline C & 0.1140 & 0.491 & 0.1217 \\
\hline
\end{tabular}

the IEEE standard characteristics contains a $C$ parameter in order to reflect the fixed tripping time caused by the inductance saturation which occurs when the input current value is greater than a threshold. For practical protection applications, the IEEE committee defined three different characteristics which were similar to the IEC standard characteristics. Table 2 summarizes the required $A, B$, and $C$ values in order to obtain the different IEEE standard relay characteristics. The visual depiction of the responses given by the three IEEE standard characteristics to the different fault current magnitudes can be seen in Fig. 3b.

$$
t=\left[\frac{A}{\left(\frac{I_{f}}{I_{p}}\right)^{B}-1}+C\right] \cdot T D S
$$

\section{Non-standard Characteristics}

This section is devoted to giving details about the studies which aimed to construct N-SCs in order to achieve protection coordination in power systems. These unconventional approaches are categorized as four groups: 1) approaches that include electrical magnitudes, 2) approaches that use different coefficients apart from the SCs, 3) mathematical approaches, 4) other approaches.

\subsection{Non-standard Characteristics Including Electrical Magnitudes}

In the past the relays that were used to detect and clear a fault depended only on the fault current value. However, today, the voltage value can also be used to diagnose the faulty part of the power system due to the fact that directional overcurrent relays (DOCRs) have generally become more accessible and are able to measure both current and voltage values on the line which they are connected to via current and voltage transformers. The previous research showed that this feature of the DOCRs creates an opportunity for the application of N-SCs 


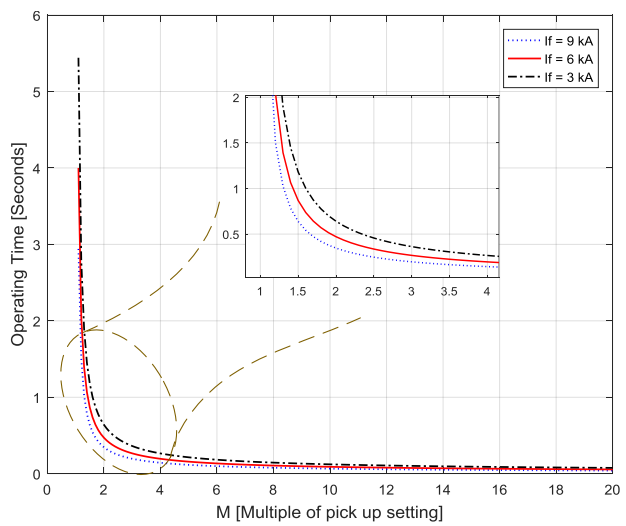

(a)

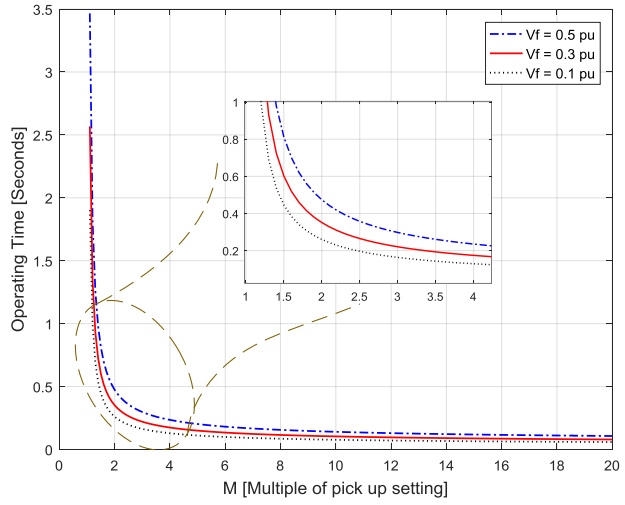

(b)

Figure 4: (a) Impact of current change on the N-SC constructed by (3) and (4) considering A = 14.5, B = 0.5, $\mathrm{C}=6.5$, and TDS $=1$, (b) Impact of voltage change on the N-SC constructed by (5) considering $\mathrm{A}=0.14, \mathrm{~B}=0.02, \mathrm{k}=1.5$, and $\mathrm{TDS}=0.1$.

\subsubsection{Current Based Characteristics}

It is still possible to generate N-SCs based merely on the current measurement, even though the current is readily used in the SCs. Studies used current in a different way apart from the SCs are summarized in this subsection.

Industrial power systems constitute a very rich environment in terms of protective devices. Most types of protective devices such as digital relays, electromechanical relays and fuses can be observed in the same industrial power system. However, in such a highly diverse environment, coordinating different types of protecting devices such as relay-fuse is a challenging task when using standard approaches. In order to deal with quite complex coordination problems in an industrial power system a N-SC was suggested in [51. In this characteristic, it was considered that the $A$ value changes dynamically with the measured current value instead of being constant. The characteristic equations used in [51] are given in (3) and (4). However, it is necessary to observe that the determination of the $A\left(I_{f}\right)$ function depends on the particular protection problem. The impact of changing fault current on N-SC characteristic which is given by (3) and (4), is illustrated in Fig. 4a

$$
\begin{aligned}
A\left(I_{f}\right) & =A \cdot e^{-\frac{I_{f}}{C}} \\
t & =\left[\frac{A\left(I_{f}\right)}{\left(\frac{I_{f}}{I_{p}}\right)^{B}-1}\right] \cdot T D S
\end{aligned}
$$

The $A$ value in (3) was defined as a constant but it was not required any more to strictly obey the standards while selecting the value of $A$. The same procedure was valid for the constant $C$ which meant it may be also freely selected. Additionally, the type of function of the (3) was decided by curve fitting method based on the set parameters of the system. The presented results showed that a dramatic decrease in OTs of the relays can be obtained introducing above-mentioned N-SC in the industrial power systems. However, it should be underlined that the new constants are needed to be adjusted for each particular case, and that generalization of the solution 
needs to be further researched by providing a formula in order to deal with protection challenges in other types of power systems.

Other studies aimed to obtain N-SCs based on the current measurement were presented in [52, 53], which combined the adaptive relay concept and non-standard approaches. The pickup current was considered as a function of the load current in these studies $\left(I_{p}\left(I_{L}\right)\right)$. However, instead of using an explicit equation, the curve fitting approach based on a polynomial equation that was presented in [54, was utilized by a software which was particularly developed for relay coordination applications. Although a very complex structure was given as an output equation by the software, not requiring setting parameters and automatic coordination is the superior features of this method.

\subsubsection{Voltage Based Characteristics}

The main idea behind utilizing the voltage value that is seen by the relay is to provide reliable relay coordination under high penetration of DG. Since the DG contributes to the fault current, the bus voltages in the system are indirectly affected by the varying fault current. One of the earliest studies that used the measured voltage value was [10]. Khaled et al. proposed (5) in which the voltage value was inserted into the equation of the IEC standard characteristic as a multiplier which decreased the relay OT in each possible fault condition. Also, it was considered that the relay OT takes a minimal value when the measured voltage value is zero, which means that a fault occurs at the contact point of relay. It should be underlined that the per unit value of the measured voltage $\left(V_{f}\right)$ is used in this equation while a new constant $k$ is utilized to adjust the contribution of the voltage. It is also noteworthy that any unique way to calculate the constant $k$ was not presented in [10] and therefore it still needs to be addressed by further research. Moreover, the voltage effect on the N-SC proposed in [10] is depicted in Fig. 4b.

$$
t=\left(\frac{1}{e^{\left(1-V_{f}\right)}}\right)^{k} \frac{A}{\left(\frac{I_{f}}{I_{p}}\right)^{B}-1} \cdot T D S
$$

The proposed N-SC in [10] was also used in [49] for a transmission system including wind power plants (WPP). Based on the relation between voltage value at the point of common coupling and fault-ride through behaviour of wind turbines, the study aimed to operate the WPP by adjusting properly the relay settings. Normally, the WPP connection status in case of any fault is determined by a critical voltage and duration of the observed voltage which are defined in the grid codes. Accordingly in [49] this maximum allowed duration was regarded as an upper limit for the backup relays which use (5). By operating the feeder protection relays before the low voltage protection of the wind turbine generator trips, the possibility of maintaining the generators connected was increased. Another significant feature of this study was that it constituted an example of the application of a non-standard approach regarding protection requirements at the transmission level, in contrast with the majority of the studies that have focused merely on distribution systems. Equation (5) was also tested under changing network topologies following power system outages in [50].

$$
t=\frac{A}{\left(\frac{I_{f}}{I_{p}}\right)^{B}-1}\left(\frac{V_{f}}{e^{k \cdot V_{f}}}\right) \cdot T D S
$$

Leveraging the benefits of a SC while devising a new characteristic was followed in [55], in which the voltage parameter was used for improving fuse-relay coordination in the presence of DG. The characteristic equation that was developed in [55] is given by (6). Similar to (5) the proposed characteristic equation also included the per-unit voltage value $\left(V_{f}\right)$ and a constant $k$. The relationship between voltage change and the N-SC characteristic 


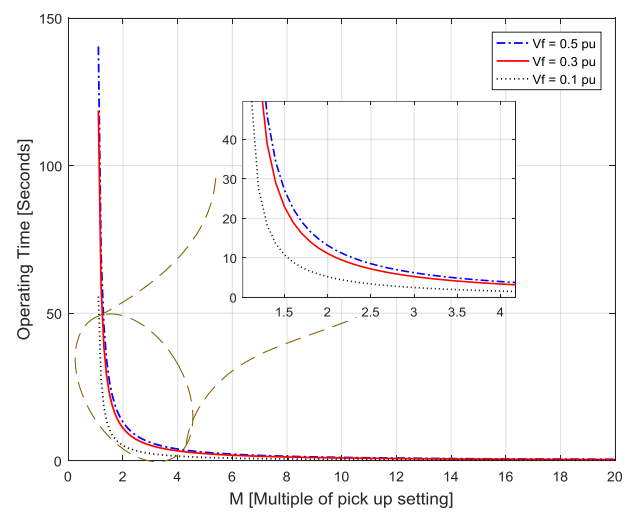

(a)

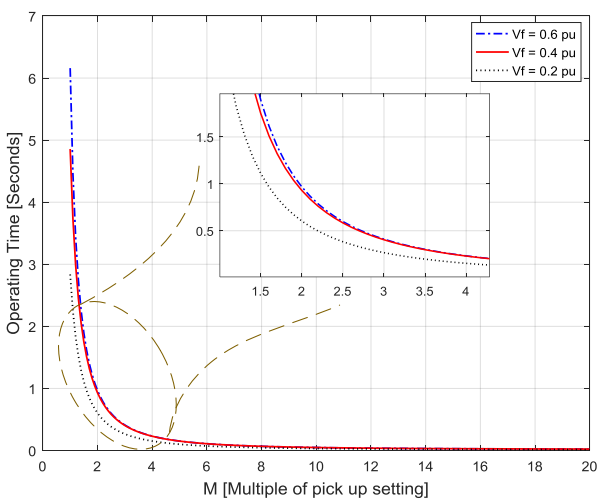

(b)

Figure 5: (a) Impact of voltage change on the N-SC characteristic constructed by 6 considering $\mathrm{A}=80, \mathrm{~B}=2, \mathrm{k}=1.71$, and $\mathrm{TDS}=1$, (b) Impact of voltage change on the N-SC characteristic constructed by 8 and $(9$ ) considering TDS $=0.5$.

proposed is visualized in Fig. 5a. Additionally, a detailed presentation of the calculation of $k$ value was given in [55] where it was stated that a monotonically decreasing characteristic may be achieved only for values of $k$ that are less than 2. It is worth noticing that the process is carried out without considering DG integration and two different equations are used to calculate $k$ for three phase-to-ground faults, or single phase-to-ground and two phase-to-ground faults. The capability of ensuring protection coordination without any communication infrastructure is an advantage of the approach that was propounded in $[55$.

$$
t=T D S \cdot \frac{\left(V_{f}\right)^{k}}{e^{V_{f}}}\left[\frac{A}{\left(\ln \left(V_{n} \frac{I_{f}}{V_{f}}\right)\right)^{B}-\left(\ln \left(V_{n} \frac{I_{\text {set }}}{V_{\text {set }}}\right)\right)^{B}}+C\right]+D
$$

A similar approach in terms of using voltage magnitudes was presented in [56], which brought a new perspective using a logarithmic function in the denominator. One can consider the presented characteristic in [56] as a combined approach because it includes both an "unconventional" mathematical expression and electrical magnitudes, as given in (7). It can be seen from (7), when the voltage measured by the relay is zero, OT of the relay depends only on the constant $D$. Also, the reason for using the natural logarithm was to restrict the high variations in current and voltage. Finally, the proposed equation was designed for communication-free protection schemes, nonetheless, the complex structure of the characteristic equation might seem challenging for users.

$$
\begin{aligned}
A & =V_{f} \cdot\left(1-V_{f}\right) \\
t & =A \cdot\left[\frac{28.2}{\left(\frac{I_{f}}{I_{p}}\right)^{2}-\left(\frac{1}{e^{\left(1-V_{f}\right)}}\right)^{2}}+0.1217\right] \cdot T D S
\end{aligned}
$$

Another form of voltage based characteristic presented in [57] is given by (8) and [9]. The N-SC was construct to improve recloser-fuse coordination in a distribution system including DG units. The presented approach has similar advantages and drawbacks with [56]. It should be underlined that when the voltage is zero, the tripping signal is generated at $t=0$ without waiting for sub-transient fault current to decrease so as to protect the circuit breaker. It is illustrated that the changes in the proposed characteristic due to voltage variation in Fig. $5 \mathrm{~b}$.

$$
t=\left(\frac{1}{1-\left(\log V_{f}\right)^{C}}\right)^{k} \frac{A}{\left(\frac{I_{f}}{I_{p}}\right)^{B}-1}
$$

A different voltage based N-SC, which is given in [10], was presented in [58] and [59]. The characteristic equation was similar to 5 although logarithmic function was used for utilization of the voltage. Herein, the 


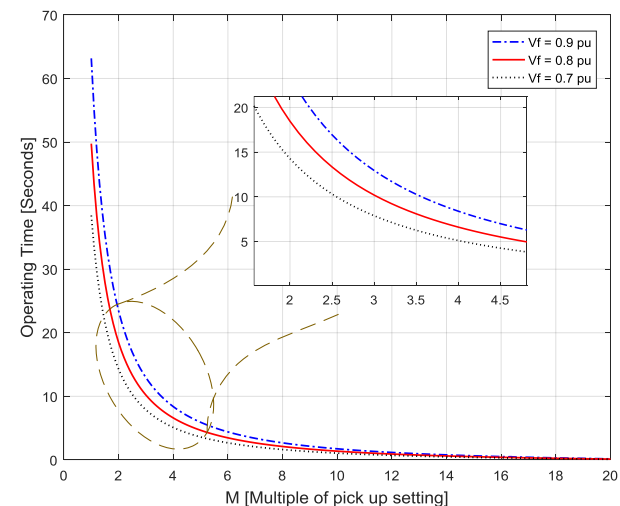

(a)

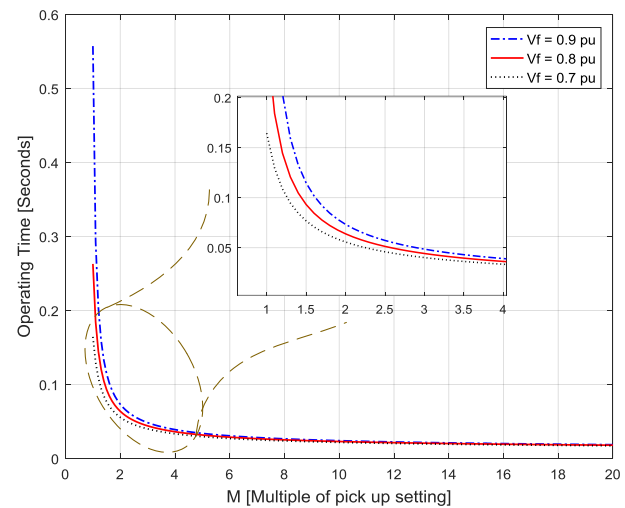

(b)

Figure 6: (a) Impact of voltage change on the N-SC characteristic constructed by 10 considering $\mathrm{A}=80, \mathrm{~B}=1.4, \mathrm{C}=1$, and $\mathrm{k}=5$, (b) The voltage effect on admittance based N-SC characteristic constructed by 12 considering $\mathrm{A}=0.0047, \mathrm{~B}=0.08$, and $\mathrm{C}=0$.

measured voltage value was added to the characteristic equation using its per unit value and voltage contribution can be controlled using the $k$ parameter. The response of the N-SC which was proposed in [58] and [59] to voltage variation is depicted in Fig. 6a.

$$
t=\frac{\log \left(V_{f}+A\right)}{M^{B}-1}+C
$$

Another approach using voltage measurement with logarithm function was proposed in 60. The characteristic equation is given in 11]. The characteristic equation does not include TDS setting, and therefore, it eliminates inheritance of the drawback of increasing OT towards the source. Moreover, the coordination is ensured by adjusting $A, B$, and $C$ in the equation. The proposed characteristic minimizes the DG effect and provides relatively low OTs, however, further investigations considering the large dimensional power network are still needed due to increasing number of variables to optimize.

\subsubsection{Admittance Based Characteristics}

Another solution for mitigating the effects of new generation power system features on protection coordination was suggested in [61], which utilized the measured admittance value. The proposed characteristic equation is given by $(12)$ and is visualized in Fig. $6 \mathrm{~b}$.

$$
t=\frac{A}{Y_{r}^{B}-1}+C
$$

The structure of the characteristic was very similar to standard equations, except for some changes such as $I_{f} / I_{p}$ value was replace with $Y_{r}$ and the equation did not include any TDS settings. In $(12), Y_{r}$ was the normalized admittance value calculated according to the 13 . Additionally, instead of using current and time settings, it was recommended to use $Y_{t}$ and the constants $A, B$, and $C$ in order to coordinate protection relays.

$$
Y_{r}=\left|\frac{Y_{m}}{Y_{t}}\right|
$$

Here $Y_{m}$ denotes the measured admittance during the fault and $Y_{t}$ is the set admittance value for the relay. It can be concluded from the equations that the relay generates tripping signal only when $\left|Y_{m}\right|>\left|Y_{t}\right|$. According to the $Y_{t}$ value, the protected line was divided into zones as if it was a distance relay and then an inverse time characteristic was assigned for every zone. The idea is that avoiding the TDS values provides an opportunity to prevent high OTs for relays which are close to the source. However, setting additional zones with unique values of 


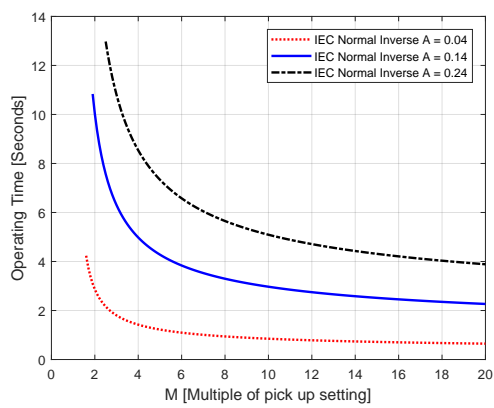

(a)

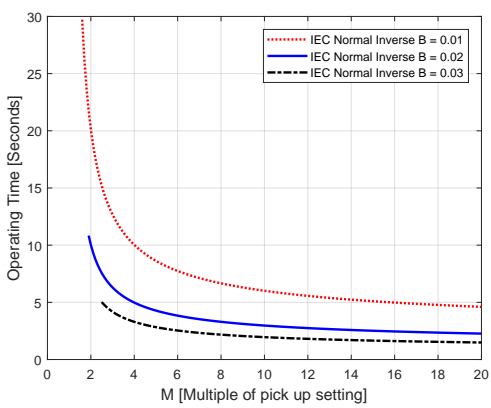

(b)

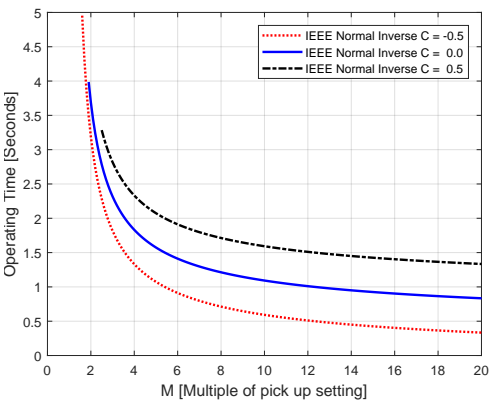

(c)

Figure 7: Effect of different coeffiencts on SCs (a) Changes in the IEC SC for different A values with B = 0.02, (b) Changes in the IEC SC for different $\mathrm{B}$ values with $\mathrm{A}=0.14$, (c) Changes in the IEEE $\mathrm{SC}$ for different $\mathrm{C}$ values with $\mathrm{A}=0.0515$ and $\mathrm{B}=0.02$.

$A, B$, and $C$ for every relay could be a challenging task for users. In addition to that, measurement and calculation of the admittance value should be also carefully considered because distribution systems have shorter lines than transmission systems. Moreover, identifying the location of a highly resistive fault which is close to end of the defined zone can be a non-trivial task in this method. Last but not the least, changing in CTI value due to the decreasing fault current can be avoided by dividing protection line into more zones, however, it could cause extra computational burden. It is worth adding that communication infrastructure is not needed to implement the suggested N-SC.

The proposed admittance based N-SC was evaluated in 62, 63. for MG applications which contained inverter based DGs with limited fault currents. It was stated that admittance based N-SC allowed to isolate faulty part of the system and the rest of the system could continue to operate in islanded mode. It was also stated that the MG protection was provided by using the admittance based N-SC even after disconnection from grid. Also, the suggested N-SC was tested for distribution networks in [48, 64]. It was well demonstrated that the inverse time characteristic can be provided independent from the changes in source impedance by using admittance based N-SC. However, it is still a limitation that the downstream relay always operates after the upstream relay due the interaction between fault currents supplied from grid and DGs.

\subsection{Non-standard Characteristics Generated by Manipulating Standard Characteristics}

This section gives detailed information about construction of N-SC by manipulating readily available SCs. This section is further divided in two subsections: First, the studies that aimed to obtain N-SCs by changing only constant parameters in the equation of SCs without making any additional changing are reviewed. Then, studies that obtained N-SC by combining two separate SCs are discussed.

\subsubsection{Non-standard Characteristics Generated by Applying Different Constant Values}

Changing the constant values independently from the ones that are given in the standard definitions is another way to construct N-SCs, or in other words, more flexible SCs. Keeping the general mathematical expression as it is helps adhering to the expected general shape of relay characteristic. As a consequence, a considerable amount of literature on protection paid particular attention to this type of N-SCs. The general approach is to consider the constants as variables that are to be optimized similar to $I_{p}$ and $T D S$ values. For illustrative purposes, the changes in SCs according to changes in relevant coefficients are depicted in Fig. 9.

Using the standard IEEE characteristic, a dual characteristic which means only one DOCR is able to detect and clean a backward fault as well as a forward one, was obtained in [65. Also, it should be emphasized that 
the constants $A, B$, and $C$ for each relay were optimized for both forward and backward operation. The results showed that adjusting the constants as variables provides a decrease in relay OT of the mesh distribution system including DG connection. Nevertheless, the proposed characteristic can further be evaluated against fault current changes due to the DG integration. It was assumed that a communication infrastructure is readily available for coordinating DOCRs with a dual characteristic in [65], however in some cases, the cost of this approach might be a limiting factor. Decreasing the total OT of relays was also achieved in [66, 67] by applying the same approach for only one direction. Additionally, a comparison between ranges of constants in [67] showed that defining wider ranges for these new variables gave better results. It is worth devoting some effort on further researching relations between DG, ranges of constant, and OTs of the relays. The $A, B$, and $C$ constants are optimized individually in 68] considering several power networks dimensions ranging from relativity small to large. In addition, the study pointed out that increasing the limits of constants decreases the solution quality. The constants $A$ and $B$ in the IEC standard characteristic were considered as variables in [69, 70, 71, 72, 73, 74, 75, 76, 77,. The studies achieved a decrease in OTs of the relays while addressing the effect of DG. Considering the three fault points in a protection zone so as to improve relay coordination was a valuable contribution of [69, 70]. Also, a significant comparison which concluded a small improvement may be achieved in terms of decreasing the total OT by choosing particular constants for each relay instead of choosing a global constant pair for all relays, was presented in [71]. The same approach was used in 72 in order to assign OCRs as backup relays for distance relays used in transmission system, by doing so, a reliable protection even when DG units are connected to the grid was ensured. Similarly, seperate optimal $A$ and $B$ values were used to improve the backup performance of DOCRs for transmission system faults in [73. Individually optimized $A$ and $B$ values for both two directions were assigned to DOCRs in [74] to provide relaxation on the standard curves and total OT was reduced. Coping with the effect of DG connection was achieved using different optimal $A$ and $B$ values for each relay in [75. As a solution to mis-coordination between relay pairs [76] suggested to assign the same optimized $A$ and $B$ values to both relays. Moreover, the study presented in [77. suggested to optimize $A$ and $B$ parameters in order to deal with protection coordination problems that arise in MGs due to islanded and grid connected operation modes. Last but not least, a relay which is able to accommodate different values for the $A$ and $B$ parameters was designed and implemented in [78].

Increasing the number of adjustable constants and using wider ranges has given better results in these type of approaches. However, this brings a significant calculation burden and even sometimes may cause lack of convergence in large dimensional networks. Especially, this could be an issue in large networks which include DG units and which are exposed to relatively more dynamic reconfiguration. Establishing a constant CTI for the total fault current range should be carefully evaluated because assigning different values to the constants $A, B$, and $C$ leads to different characteristics between relay pairs.

Instead of considering all the constants as optimization variables, some researchers aimed to combine various SCs for protection purposes. The common principle in these studies was to allow one relay to use a SC, e.g. NI, while also allowing the other relay to use another type of SC, e.g. VI. General application in this type of studies was to use an extra variable which denotes the type of characteristic while formulating the optimization problem. The related variable set was defined utilizing the SCs. For example, set of characteristic variables was defined as it consisted of only the IEC SCs in [79, 80, 81, 82, 83, 84] while optimization algorithm was able to choose a characteristic from eight different SCs for a relay in 85, 86. Similarly, only the IEC and the IEEE standard characteristics pool was used in [87] while this pool was extended by adding IAC and U.S. curves in [88]. It should be noted that although decrease in total OT of the relays was possible, keeping CTI as constant was almost 
impossible between the relay pairs with different characteristics. However, the approach could be useful in N-SC applications in which the power system is divided into different zones and the same N-SC is applied within one zone. Apparently, by doing so, the CTI variance throughout the whole fault current range could be minimized but never be completely avoided.

\subsubsection{Non-standard Characteristics Generated by Combining Standard Characteristics}

N-SCs can be devised by using two or more standard curves. This approach was implemented in 89 in order to achieve coordination between a relay, which is used for protection against ground faults, and a fuse. Basically, it is usually desired to use primarily the relay for lower fault currents in order to avoid unnecessary blows of fuses in case of temporary high currents and to use primarily the fuse for higher fault currents. However, there is a significantly wide range of currents for which both protective devices may be operate non-selectively. Minimizing this current range to operate relay-fuse pairs in a selective manner, a non-traditional $\mathrm{SC}$ was utilized in [89] by mixing two IEC standard equations and applying a completely N-SC defined by user. Deciding which SC should be used by relay was made according to a comparison of measured and previously defined current values. The paper provided a solid solution for the coordination of ground OCRs and fuses by nearly eliminating the simultaneous operation using N-SCs. Based on these results, the approach could further be expanded to implement other types of characteristics in order to detect the ground fault. However, the particular specifications of ground overcurrent faults, such as extremely low pick-up currents should be taken into account while defining a new N-SCs. In addition, the proposed N-SC should keep its inverse characteristic even for the higher $I_{f} / I_{p}$ ratios. A different aspect which needs to be evaluated could be the dynamic behaviour of the characteristic. Thus, the suggested characteristics need to be carefully evaluated in terms of dynamic response especially for the fault currents which are nearly at the junctions of the characteristics. Two different IEC SCs were utilized jointly in 90 regarding the critical fault clearance time DG units to ensure stable operation in islanded part of the system after disconnection. The study provides the necessary formulation in terms of combining protection and stability, nevertheless, the effect on DG units may be further researched by utilizing different N-SCs.

Another idea to implement different characteristics rather than SCs was to combine a readily available SC with a definite time characteristic. It was demonstrated in [91] that in case the relay coordination was lost due to the DG connection, using a combined characteristic by only setting a definite time characteristic may be a low-cost option to ensure relay coordination again. The improved version of this approach was implemented in [92, 93, by adding extra definite time steps. The resulting curve was a combination of one inverse time characteristic and two or three definite time curves. It should be noted that a practical and flexible coordination concept was achieved using these methods, however, providing constant CTI and increase in OT towards the source needs to be further researched.

The study that aimed to divide fault current range into two equal sections in order to decrease OTs of the relays while ensuring protection coordination even when multiple fault locations are considered was presented in [94. In this paper, the equation of the IEC standard NI characteristic was used. Dividing the fault current range increased the number of set variables per relay. So, in the paper, two pairs of TDS and $I_{p}$ settings for each relay were optimized and lower OTs were obtained while considering multiple fault locations. Nevertheless, it was noted that dividing the fault current range into more sections brings calculation burden together. Thus, as long as the trade-off between increasing the pairs to be optimized by slicing the fault current range and decreasing the OTs of the relays is managed, the approach will be useful for further investigations. 


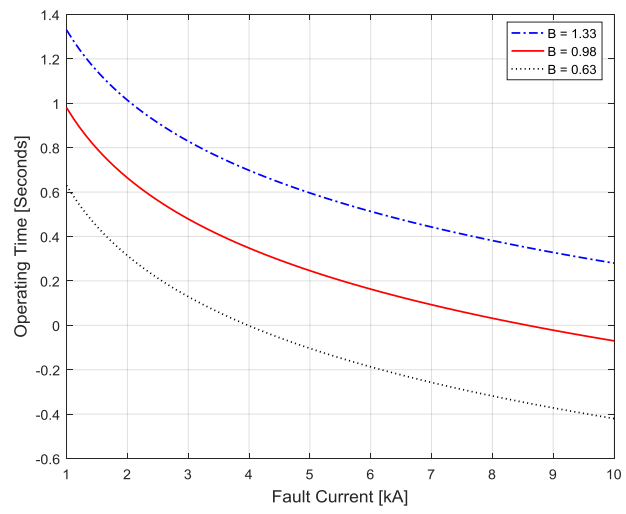

(a)

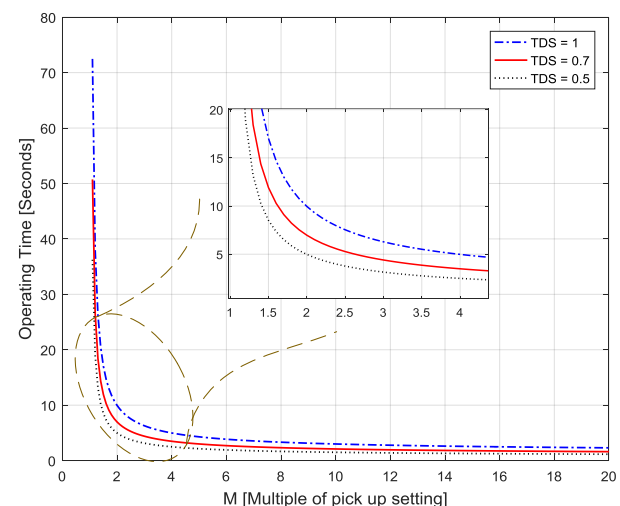

(b)

Figure 8: (a) The N-SC characteristic constructed by 14 considering A = -1.05, (b) The N-SC characteristic constructed by 15

\subsection{Mathematical Approaches for Constructing Non-standard Characteristics}

This section reviews the studies that aimed to construct N-SCs using mathematical expression differently from the standard ones. Even though every non-standard approach can be considered as "mathematically different", the approaches that used a backbone apart from exponential form are discussed in this section.

To mathematically express the operational characteristics of fuses, logarithmic functions are widely used. Inspiring from this fundamental power system protection characteristic, a new relay characteristic was offered in [95. The suggested characteristic equation is given in (14). Moreover, graphical illustration of the N-SC for the different $B$ coefficients can be seen from Fig. 8a. In contrast with the standard equations of characteristics, $A$ and $B$ were not considered as constants and values of both were calculated to coordinated the relays.

$$
t=A \log \left(I_{f}\right)+B
$$

Equation 15 which was roughly similar to the logarithmic approach in (14), was suggested in [96] considering protection challenges in MGs. Even though the proposed characteristic equation was able to detect low level fault currents, concerning application at higher current levels such as distribution systems or transmission systems could be achieved by improving or re-establising the equation. Fig. 8b depicts changes in the N-SC devised in 96 according to the TDS variations.

$$
t=T D S \frac{3}{\log \left(I_{f}\right)}
$$

In order to extend the operating temperature range of the relay and benefit from the less maintenance advantage of the microprocessor based relays an OCR was developed in 97. The characteristic equation of the proposed relay is given in (16). Although the general form of the characteristic was very similar to the standard ones, it can be seen from the (16) that constants were defined as they were dependent to time at ten times of operating current, $t_{10}$. Three different characteristics were obtained in the paper which utilized the $(16)$ with different $A$ and $B$ pairs. It should be noted that the details of the so complex empirical calculations of the constants are not given here for the sake of clarity. Nevertheless, as stated in [97, there was no a unique perfect characteristic that was valid for all protection cases, which also meant that it might be meaningful to use the constants depended on desired protection requirements in some cases.

$$
t=\frac{A\left(t_{10}\right)}{\left(\frac{I_{f}}{I_{p}}\right)-1}+B\left(t_{10}\right)
$$




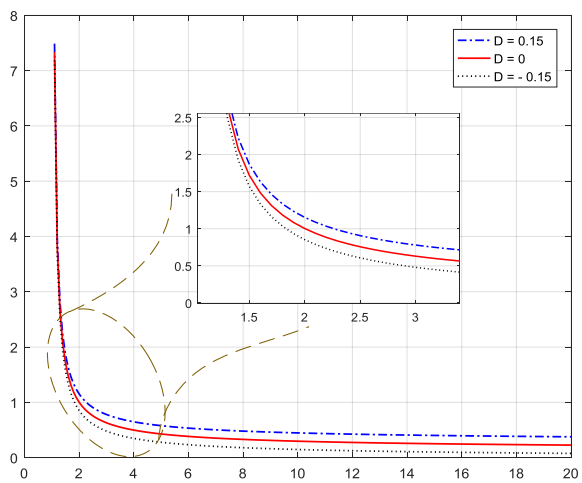

(a)

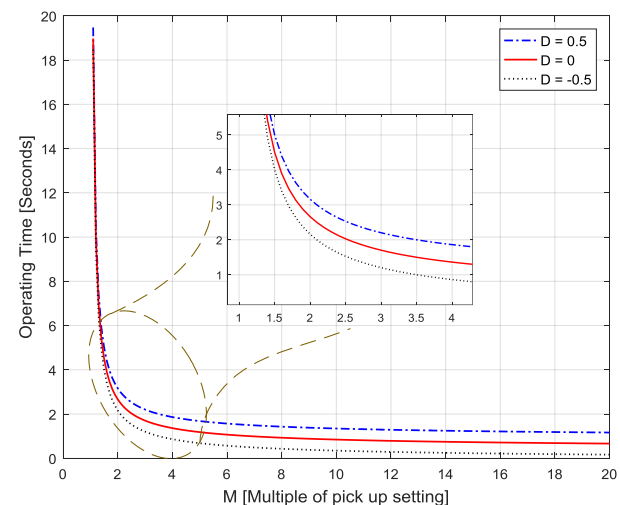

(b)

Figure 9: (a) The N-SC characteristic constructed by 17 considering $\mathrm{A}=0.14, \mathrm{~B}=0.02, \mathrm{C}=0$, and TDS $=1$, (b) The N-SC characteristic constructed by 17 considering $\mathrm{A}=0.0515, \mathrm{~B}=0.02, \mathrm{C}=0.114$, and $\mathrm{TDS}=1$.

Preserving the general form of SCs, a shifting principle was implemented in 98] and 99. A similar backbone to the SCs is used considering the present constants $A$ and $B$ as variables. The proposed characteristic equation is given in (17). It should be noted that the constant $C$ was taken as zero in 98. Equation (17) allowed the user to assign desired values to $D$ so as to shift the curve along the time axis while preserving original the shape. In theory, since the variable part of the equation is zero when $C$ is zero (as in 98]) and the fault current is infinite, the desired OT for a relatively high fault current may be taken as a lower bound for $D$. The same equation was used in [99. with the purpose of developing a software model capable of not only simulate the electromechanical relay characteristics but also custom characteristics. Four different constants were used to adjust the N-SC, however, it is noteworthy that computational burden could increase especially in large dimensional coordination problems. Furthermore, response of N-SC proposed in 98] to the different $C$ values is visualized in Fig. 9a while response of N-SC proposed in $[99$ to the different $D$ values is sketched in Fig. 9b

$$
t=\left[\frac{A}{\left(\frac{I_{f}}{I_{p}}\right)^{B}-1}+C\right] \cdot T D S+D
$$

\subsection{Other Non-standard Characteristics}

In this section, studies that either proposed an unconventional method for the construction of N-SCs or methods that are not backed by a sufficient number of literature studies in order to be separately classified are presented.

It was suggested in [100] to adjust the relay characteristic according to maximum allowed temperature value of the conductor by using specific current and time values regarding the temperature limit of the conductor. In this study an inverse time characteristic was obtained by using the transient thermal conductor curves. Moreover, parameters that might affect the conductor temperature such as wind speed, current, solar gain potential of the conductor, and emissivity were evaluated.

In a radial feeder that includes a number of relays with SCs, an increase in the OT of the relays closer to the distribution transformer is noticed because of the CTI. Furthermore, since the inverse TCCs are close to each other for low fault currents, providing a sufficient CTI could be an issue. As a remedy to this challenge of the SCs, a non-standard approach using a look-up table containing data related to operating times and fault currents was proposed in [101. In this non-standard approach, the main idea was to construct a table for each relay using its near-end and far-end fault currents as well as their operating times. In order to form the look-up table, it was 
assumed that each relay should be operated at the lowest possible time, i.e., $0.1 \mathrm{~s}$ for a near-end fault in their main protection zone. Afterwards, the operation time for far-end faults was calculated by adding the CTI to the primary operation time. By doing so, the points necessary for the main protection zone of each relay were obtained. Then, in order to calculate data for the secondary operation zone of each relay, the operation time for the far-end fault of the other relay that is used as backup, was used. The calculation was made by adding again the CTI value to the operation time for far-end fault in main protection zone of primary relay. Once entering the primary and backup operating information into each relay, the rest of characteristics were calculated utilizing internal linear interpolating feature of the relays. Loads with high starting currents, e.g. electrical machines, etc. were also taken into account while constructing the TCCs. As a consequence, the characteristics were modified so as to allow temporary overcurrents for the relatively short starting periods of the special loads. This idea is characterized by its simple but solid structure. Nevertheless, some improvements could be achieved using nonlinear curves that are expected to decrease the total OT. Moreover, testing the proposed approach in a mesh structure is needed. Additionally, the approach should be applied to power systems including DG units in order to observe the proposed characteristic under changing fault currents. A possible increase in OTs due to changes in the fault current could be prevented by using a tabular form that also includes another electrical parameter except for currents.

In order to account for the probabilistic nature of the fault current magnitudes, a stochastic mixed integer linear programming model of relay coordination was developed in [102. It was assumed that the fault current space has a discretized form. Then, based on the solution of the formulated problem the TCC was constructed using obtained optimal OTs for each fault current interval.

\subsection{Experimental Studies on Non-standard Characteristics}

Along with the theoretical efforts to construct N-SC, a limited number of experimental results related to N-SC has been reported in the literature. Dewadasa et al. [48] tested the admittance based characteristic which is given in (12). The experiments that aimed to test the performance of the proposed characteristic, were carried out using an experimental setup operated under 230V. Single phase-to-ground faults were created in order to evaluate the response of proposed characteristic taking into account different fault locations and source impedances. The relay performance was also investigated considering cases in which the experimental setup included a DG unit. The results proved that the theoretically constructed admittance based characteristic can be applicable to an actual protection system. However, the experimental research could be extended by evaluating different types of faults, higher voltage levels, or different penetration levels and types of DG units. Another experimental study was presented by Park et al. in [78]. In this study, three types of faults, namely single phase-to-ground, two phase-to-ground, and three phase-to-ground were considered in order to test the proposed non-standard approach, which comprised a SC with different coefficients. The tests were conducted using an experimental setup which included a CORDIC processor as the relay and a software named Electromagnetic Test Program (EMTP) to simulate the power system. The designed relay was tested using a model of two 75km-transmission lines which were operated at $154 \mathrm{kV}, 60 \mathrm{~Hz}$. The results showed that an increase in the coefficient $B$ led to a decrease in OT of the relay.

Singh et al. 73 validated the relay operation with N-SC that constructed by applying different constants to the IEC SC. The tests were conducted using a real-time digital simulator, which was used to simulate the power system, and Micom P442 digital relays. The presented hardware-in-the-loop simulation results cover different fault resistances in the range of 0 to 50 as well as a combination of phase and ground faults. In addition, several fault locations such that $2 \%, 20 \%, 90 \%$, and $98 \%$ were also considered and an impairment in the relay performance was 
Table 3: Summary of Non-standard Characteristics

\begin{tabular}{|c|c|c|c|c|}
\hline Non-St & adard Characteristics & Main Feature & Pros & Cons \\
\hline \multirow{3}{*}{$\begin{array}{l}\text { Including } \\
\text { Electrical } \\
\text { Magnitudes }\end{array}$} & $\begin{array}{l}\text { Current Based } \\
51,52.53\end{array}$ & $\begin{array}{l}\text { Fault current is used as a variable to } \\
\text { obtain the value of parameter } A \\
\text { of the characteristic. }\end{array}$ & $\begin{array}{l}\text { The characteristic is dynamically } \\
\text { updated; particularly suitable } \\
\text { for industrial power systems. }\end{array}$ & $\begin{array}{l}\text { Valid in certain conditions; } \\
\text { has to be updated for each case. }\end{array}$ \\
\hline & 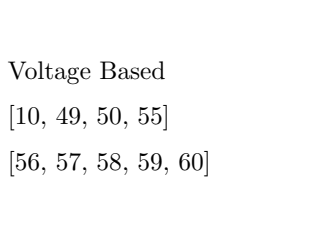 & $\begin{array}{l}\text { An expression containing the voltage } \\
\text { value is used as a multiplier. Used } \\
\text { for protection that does not rely } \\
\text { on communication and for mitigat- } \\
\text { ing the effect of DG. }\end{array}$ & $\begin{array}{l}\text { The OT time of the } \\
\text { relay is decreased; } \\
\text { robust operation under } \\
\text { DG penetration. }\end{array}$ & $\begin{array}{l}\text { Complexity of mathematical expressions; extra } \\
\text { parameter to control the voltage multiplier; } \\
\text { limited or no experimental validation. }\end{array}$ \\
\hline & $\begin{array}{l}\text { Admittance Based } \\
61,62,63.68,64\end{array}$ & $\begin{array}{l}\text { Using the admittance } \\
\text { value } Y_{r} \text { instead of } \\
\text { currents } I_{f} / I_{p} \text { and } \\
\text { not including the TDS value. }\end{array}$ & $\begin{array}{l}\text { High operating times are } \\
\text { prevented due to the ab- } \\
\text { sence of TDS; } \\
\text { experimentally validated. }\end{array}$ & $\begin{array}{l}\text { Additional protection zones with unique } \\
\text { parameter values for each relay are required; } \\
\text { increased computational burden due to } \\
\text { changes in the CTI value in each zone. }\end{array}$ \\
\hline $\begin{array}{l}\text { Manipulating } \\
\text { Standard } \\
\text { Curves }\end{array}$ & 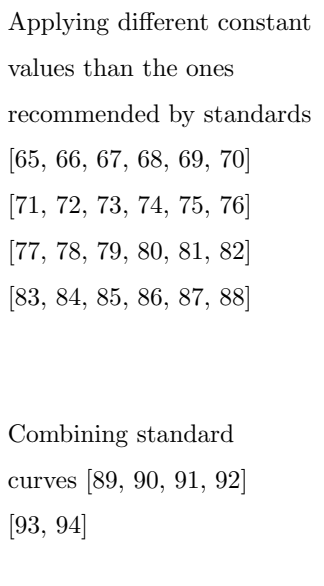 & $\begin{array}{l}\text { Optimization of the } \\
\text { constants } A, B \text {, and } C \\
\text { while maintaining the } \\
\text { general shape of the curve. }\end{array}$ & $\begin{array}{l}\text { The OT of the relay } \\
\text { is decreased; } \\
\text { more flexible curves; } \\
\text { experimentally validated } 78 .\end{array}$ & $\begin{array}{l}\text { Curves are relatively less flexible in comparison with } \\
\text { curves obtained by altering the values of the con- } \\
\text { stants; prone to improper operation due to changes } \\
\text { in the fault currents induced by changes in network } \\
\text { topology; little or no experimental validation. }\end{array}$ \\
\hline $\begin{array}{l}\text { Mathematical } \\
\text { Approaches } \\
95.96 .97 \\
98.99 .\end{array}$ & 95. 96. 97 & $\begin{array}{l}\text { Mainly based on the IEC or the } \\
\text { IEEE standard characteristic. The } \\
\text { only change is that an extra term } \\
\text { added to the characteristic equation. }\end{array}$ & $\begin{array}{l}\text { Flexibility in characteristics; } \\
\text { lower OTs compared to } \\
\text { standard characteristics. }\end{array}$ & $\begin{array}{l}\text { The extra term increases the computational burden; } \\
\text { Changes in current due to the topological changes } \\
\text { cannot be mitigated using only the current param- } \\
\text { eter; No experimental results have been reported. }\end{array}$ \\
\hline \multirow{3}{*}{$\begin{array}{l}\text { Other } \\
\text { Non-standard } \\
\text { Approaches } \\
100,101\end{array}$} & 100 & $\begin{array}{l}\text { Obtains a TCC based on } \\
\text { variable temperature of } \\
\text { conductor. }\end{array}$ & $\begin{array}{l}\text { Provides flexible curves in } \\
\text { the range of allowed } \\
\text { conductor temperatures. }\end{array}$ & $\begin{array}{l}\text { Lack of other electrical parameters; } \\
\text { no experimental results } \\
\text { have been reported. }\end{array}$ \\
\hline & 101 & $\begin{array}{l}\text { Uses a tabular form to } \\
\text { construct a piece-wise linear } \\
\text { characteristic. }\end{array}$ & $\begin{array}{l}\text { Ensures the least possible } \\
\text { OT for each relay for its } \\
\text { primary zone; constant CTI } \\
\text { for the whole protection range. }\end{array}$ & $\begin{array}{l}\text { Not evaluated for dynamic changes in power } \\
\text { system conditions; no experimental results } \\
\text { have been reported. }\end{array}$ \\
\hline & 102 & $\begin{array}{l}\text { Builds TCC discretely using } \\
\text { a probabilistlic approach. }\end{array}$ & $\begin{array}{l}\text { Does not need commu- } \\
\text { nication infrastructure; } \\
\text { lower OT can be obtained. }\end{array}$ & $\begin{array}{l}\text { Applicable only for radial systems; does not } \\
\text { include other electrical parameters; no experi- } \\
\text { mental results have been reported. }\end{array}$ \\
\hline
\end{tabular}


observed at endpoints of the line. The outcome of the experiments was consistent with the simulation results. The study evaluated the N-SC application from many aspects of protection, nevertheless, assessment of the real-time performance of the considered N-SC under DG penetration in a larger network could be an interest of future research.

\section{Recommendations for Future Studies}

Based on the literature studies that were presented in this paper, the necessity of re-assessing protection systems in terms of utilizing N-SCs due to changes in power networks such as DG integration, MG operation, dynamic reconfiguration, etc., is rendered evident. In this section gaps in the literature are identified and directions for future studies are recommended. The main topics related to N-SC based protection that should receive more attention in future studies include:

- Using the electrical parameters in the characteristic equations in a different manner from the standard ones is a promising solution to adapt the protection systems to the requirements of modern power systems. Nevertheless, almost all of the propounded approaches are case-depended and therefore need the calculation of custom parameters. Thus, further research that aims to define a global characteristic is still required.

- Dealing with the challenges of protection systems in modern power systems by using the same characteristics as in standards with slight differences such as utilizing different coefficients or combining more than one standard characteristics, is well reported in the literature. However, defining a range for each coefficient so as to eliminate the risk of not achieving convergence, especially in large networks which are exposed to heavy DG penetration and dynamic reconfiguration is worth researching. Besides, the proposed characteristic in this category should demonstrate constant CTI when different coefficients are assigned to the characteristics. Moreover, dynamic response of characteristic that is an outcome of a combination of characteristic should be validated around the junction point(s).

- The application of mathematically innovative structures is always valuable in constructing N-SC. Yet, it is able to bring a new perspective via devising a N-SC approach that includes both unconventional electrical parameters and a novel mathematical structure.

- It should be underlined that minimizing the effect of CTI on the relay OT in its main protection zone towards the distribution transformer could be achieved using a strategy as in 61] or in [101. Nonetheless, the approach in 61] requires a detailed coordination process that might be improved while the approach in 101 should be verified for applications of power systems including DG units by using a tabular form that also includes another electrical parameter except for the measured current.

- It is also worth emphasizing that protection studies that scope N-SC utilization in industrial power systems have not been well established. As a consequence, devising N-SCs taking into account the peculiarities of industrial power systems, e.g. cold-load-inrush currents, is still an open topic.

- Given the limited number of experimental results in the literature, it is worth devoting effort to conducting research which specifically focusses on the application of $\mathrm{N}-\mathrm{SC}$ while addressing the special requirements of modern power systems.

\section{Conclusion}

This paper reviewed the non-standard characteristics (N-SCs) which were used in protection coordination studies. The limitations and opportunities of these studies were also evaluated. Because of the recent evolutions 
in power systems such as the proliferation of distributed generation (DG), microgrid (MG) operation, dynamic reconfiguration, etc., operational characteristics of the power systems have changed. In the power systems of the future, it is expected to observe bi-directional power flows which cause changes in both current direction and magnitudes. Thus, it is important to revise conventional protection schemes which are based only on current measurements in order to make the protection systems compatible with these new features of power systems. Moreover, the digital overcurrent relays (OCRs) are now a reasonable option to implement the N-SCs and therefore they can be considered as a decent solution for different kinds of power system applications. It should be highlighted that a widely acceptable N-SC has not been presented in the literature so far. It is quite interesting that the current situation is very similar to the situation before the publication of standard characteristic (SCs). In this paper, studies aiming to devise N-SCs for protection systems were examined also in terms of criteria and methods that were used. The features that a robust relay characteristic should satisfy are listed as the outcome of this review study:

- Asymptotic behaviour at the set point(s) of the control parameter(s).

- High sensitivity even for topologies with low fault currents.

- Ensuring relatively high operating time (OT) for far end faults and low OT for near end faults.

- Monotonously decreasing characteristic between the $O T_{\min }$ and $O T_{\max }$ according to change in control parameter.

- Easy coordination considering primary and backup operations.

- No increase in primary relay OT for a fault in main zone due to the coordination with other relays.

- Providing the constant coordination time interval (CTI) as much as possible over the entire fault current range between $I_{f_{\min }}$ and $I_{f_{\max }}$, or any other control parameter range.

- Tolerating the temporary high currents such as starting currents of motors, cold-load pickup currents, etc.

- To be compatible with other protective equipment such as reclosers, fuses, etc.

- Robust against all possible topology changes, e.g. DG connection, reconfiguration, or islanded operation.

- Low OTs for all fault types as much as possible.

- Compatible with the communication-free operation.

It should also be indicated that constructing a characteristic that satisfies all the aforementioned requirements might be an extremely difficult task that may be characterized as impossible. Nevertheless, for further research, a reasonable compromise might be determined such as to provide a characteristic that reflects the listed requirements as much as possible. Table 3 encapsulates remarks on the N-SCs which were discussed in this paper, by presenting advantages and disadvantages of each approach.

\section{Acknowledgements}

Hasan Can Kılıçkıran would like to acknowledge the support of TUBITAK (The Scientific and Technological Research Council of Turkey) BIDEB 2214-A under the project code 1059B141601327.

\section{References}

[1] A. Pathirana, A. Rajapakse, N. Perera, Development of a hybrid protection scheme for active distribution systems using polarities of current transients, Electric Power Systems Research 152 (2017) 377-389.

[2] H. F. Habib, A. Mohamed, M. El Hariri, O. A. Mohammed, Utilizing supercapacitors for resiliency enhancements and adaptive microgrid protection against communication failures, Electric Power Systems Research 145 (2017) $223-233$. 
[3] S. Kong, H.-C. Jo, Y.-M. Wi, S.-K. Joo, Optimization-based reconfiguration method for power system incorporating superconducting fault current limiter failure, IEEE Transactions on Applied Superconductivity 26 (4) (2016) 1-4.

[4] S. T. Hamman, K. M. Hopkinson, J. E. Fadul, A model checking approach to testing the reliability of smart grid protection systems, IEEE Transactions on Power Delivery 32 (6) (2017) 2408-2415.

[5] Z. Zhang, P. Crossley, L. Li, A positive-sequence-fault-component-based improved reverse power protection for spot network with PV, Electric Power Systems Research 149 (2017) 102-110.

[6] D. S. Alkaran, M. R. Vatani, M. J. Sanjari, G. B. Gharehpetian, A. H. Yatim, Overcurrent relays coordination in interconnected networks using accurate analytical method and based on determination of fault critical point, IEEE Transactions on Power Delivery 30 (2) (2015) 870-877.

[7] F. B. Costa, A. Monti, S. C. Paiva, Overcurrent protection in distribution systems with distributed generation based on the real-time boundary wavelet transform, IEEE Transactions on Power Delivery 32 (1) (2017) 462-473.

[8] A. G. Phadke, J. S. Thorp, Computer relaying for power systems, John Wiley \& Sons, 2009.

[9] M. Abdel-Salam, R. Kamel, K. Sayed, M. Khalaf, Design and implementation of a multifunction DSP-based-numerical relay, Electric Power Systems Research 143 (2017) 32-43.

[10] K. A. Saleh, H. Zeineldin, A. Al-Hinai, E. F. El-Saadany, Optimal coordination of directional overcurrent relays using a new time-current-voltage characteristic, IEEE Transactions on Power Delivery 30 (2) (2015) 537-544.

[11] ABB, 615 Series Technical Manual, https://library.e.abb.com, online accessed; 22 November 2017 (2017).

[12] AREVA, Directional/Non-Directional Overcurrent Protection, http://mt.schneider-electric.be online accessed; 24 November 2017 (2017).

[13] SIEMENS, SIPROTEC 5 Overcurrent Protection 7SJ82/7SJ85, https://cache.industry.siemens.com, online accessed; 24 November 2017 (2017).

[14] E. Sorrentino, Behavior of induction disc overcurrent relays as a function of the frequency, Electric Power Systems Research 143 (2017) 474-481.

[15] D. J. Hill, L. W. Bruehler, C. J. Bohrer, Why wait? System-wide benefits from custom overcurrent relay characteristics, in: Petroleum and Chemical Industry Conference, 2009. PCIC 2009. 2009 Record of Conference Papers-Industry Applications Society 56th Annual, IEEE, 2009, pp. 1-9.

[16] M. Monadi, M. A. Zamani, J. I. Candela, A. Luna, P. Rodriguez, Protection of AC and DC distribution systems embedding distributed energy resources: A comparative review and analysis, Renewable and Sustainable Energy Reviews 51 (2015) $1578-1593$.

[17] P. T. Manditereza, R. Bansal, Renewable distributed generation: The hidden challenges-A review from the protection perspective, Renewable and Sustainable Energy Reviews 58 (2016) 1457-1465.

[18] M. Singh, Protection coordination in distribution systems with and without distributed energy resources-a review, Protection and Control of Modern Power Systems 2 (1) (2017) 27.

[19] B. J. Brearley, R. R. Prabu, A review on issues and approaches for microgrid protection, Renewable and Sustainable Energy Reviews 67 (2017) 988-997.

[20] S. A. Hosseini, H. A. Abyaneh, S. H. H. Sadeghi, F. Razavi, A. Nasiri, An overview of microgrid protection methods and the factors involved, Renewable and Sustainable Energy Reviews 64 (2016) 174-186.

[21] J. Kennedy, P. Ciufo, A. Agalgaonkar, A review of protection systems for distribution networks embedded with renewable generation, Renewable and Sustainable Energy Reviews 58 (2016) 1308-1317.

[22] S. A. Gopalan, V. Sreeram, H. H. Iu, A review of coordination strategies and protection schemes for microgrids, Renewable and Sustainable Energy Reviews 32 (2014) 222-228.

[23] D. M. Bui, S.-L. Chen, Fault protection solutions appropriately proposed for ungrounded low-voltage AC microgrids: Review and proposals, Renewable and Sustainable Energy Reviews 75 (2017) 1156-1174.

[24] D. M. Bui, S.-L. Chen, K.-Y. Lien, Y.-R. Chang, Y.-D. Lee, J.-L. Jiang, Investigation on transient behaviours of a uni-grounded low-voltage AC microgrid and evaluation on its available fault protection methods: Review and proposals, Renewable and Sustainable Energy Reviews 75 (2017) 1417-1452.

[25] P. M. Anderson, Power system protection, Wiley, 1998

[26] S. H. Horowitz, A. G. Phadke, Power system relaying, Vol. 22, John Wiley \& Sons, 2008.

[27] A. G. Phadke, W. Peter, D. Lei, V. Terzija, Improving the performance of power system protection using wide area monitoring systems, Journal of Modern Power Systems and Clean Energy 4 (3) (2016) 319-331.

[28] H. M. Zeineldin, H. H. Sharaf, E. El-Saadany, Protection coordination for microgrids with grid-connected and islanded capabilities 
[29] M. Y. Shih, C. A. C. Salazar, A. C. Enríquez, Adaptive directional overcurrent relay coordination using ant colony optimisation, IET Generation, Transmission \& Distribution 9 (14) (2015) 2040-2049.

[30] V. C. Nikolaidis, E. Papanikolaou, A. S. Safigianni, A communication-assisted overcurrent protection scheme for radial distribution systems with distributed generation, IEEE Transactions on Smart Grid 7 (1) (2016) 114-123.

[31] V. N. Rajput, K. S. Pandya, Coordination of directional overcurrent relays in the interconnected power systems using effective tuning of harmony search algorithm, Sustainable Computing: Informatics and Systems 15 (2017) 1-15.

[32] K. A. Saleh, H. H. Zeineldin, E. F. El-Saadany, Optimal protection coordination for microgrids considering n-1 contingency, IEEE Transactions on Industrial Informatics.

[33] S. Gokhale, V. Kale, An application of a tent map initiated chaotic firefly algorithm for optimal overcurrent relay coordination, International Journal of Electrical Power \& Energy Systems 78 (2016) 336-342.

[34] D. K. Ibrahim, E. E. D. A. El Zahab, S. A. E. A. Mostafa, New coordination approach to minimize the number of re-adjusted relays when adding DGs in interconnected power systems with a minimum value of fault current limiter, International Journal of Electrical Power \& Energy Systems 85 (2017) 32-41.

[35] A. Colmenar-Santos, C. Reino-Rio, D. Borge-Diez, E. Collado-Fernández, Distributed generation: A review of factors that can contribute most to achieve a scenario of DG units embedded in the new distribution networks, Renewable and Sustainable Energy Reviews 59 (2016) 1130-1148.

[36] K. El Arroudi, G. Joos, Performance of interconnection protection based on distance relaying for wind power distributed generation., IEEE Transactions on Power Delivery.

[37] Y. Ates, M. Uzunoglu, A. Karakas, A. R. Boynuegri, A. Nadar, B. Dag, Implementation of adaptive relay coordination in distribution systems including distributed generation, Journal of Cleaner Production 112 (2016) 2697-2705.

[38] V. A. Papaspiliotopoulos, G. N. Korres, V. A. Kleftakis, N. D. Hatziargyriou, Hardware-in-the-loop design and optimal setting of adaptive protection schemes for distribution systems with distributed generation, IEEE Transactions on Power Delivery 32 (1) (2017) 393-400.

[39] F. Coffele, C. Booth, A. Dyśko, G. Burt, Quantitative analysis of network protection blinding for systems incorporating distributed generation, IET Generation, Transmission \& Distribution 6 (12) (2012) 1218-1224.

[40] T. M. Masaud, R. D. Mistry, Fault current contribution of renewable distributed generation: An overview and key issues, in: 2016 IEEE Conference on Technologies for Sustainability (SusTech), IEEE, pp. 229-234.

[41] N. Nimpitiwan, G. T. Heydt, R. Ayyanar, S. Suryanarayanan, Fault current contribution from synchronous machine and inverter based distributed generators, IEEE Transactions on Power Delivery 22 (1) (2007) 634-641.

[42] E. Dehghanpour, H. Karegar, R. Kheirollahi, T. Soleymani, Optimal coordination of directional overcurrent relays in microgrids by using cuckoo-linear optimization algorithm and fault current limiter, IEEE Transactions on Smart Grid.

[43] S. F. Zarei, M. Parniani, A comprehensive digital protection scheme for low-voltage microgrids with inverter-based and conventional distributed generations, IEEE Transactions on Power Delivery 32 (1) (2017) 441-452.

[44] D. S. Kumar, D. Srinivasan, T. Reindl, A fast and scalable protection scheme for distribution networks with distributed generation, IEEE Transactions on Power Delivery 31 (1) (2016) 67-75.

[45] R. Mohanty, A. K. Pradhan, Protection of smart DC microgrid with ring configuration using parameter estimation approach, IEEE Transactions on Smart Grid.

[46] IEC, Electrical relays-part 3: Single input energizing quantity measuring relays with dependent or independent time, 60255-3.

[47] IEEE, Standard inverse-time characteristic equations for overcurrent relays, std c37.112-1996.

[48] M. Dewadasa, A. Ghosh, G. Ledwich, M. Wishart, Fault isolation in distributed generation connected distribution networks, IET Generation, Transmission \& Distribution 5 (10) (2011) 1053-1061.

[49] K. A. Saleh, M. S. El Moursi, H. H. Zeineldin, A new protection scheme considering fault ride through requirements for transmission level interconnected wind parks, IEEE Transactions on Industrial Informatics 11 (6) (2015) 1324-1333.

[50] N. Bayati, A. Dadkhah, S. Sadeghi, B. Vahidi, A. E. Milani, Considering variations of network topology in optimal relay coordination using time-current-voltage characteristic, in: 2017 IEEE International Conference on Environment and Electrical Engineering and 2017 IEEE Industrial and Commercial Power Systems Europe (EEEIC/I\&CPS Europe), IEEE, pp. 1-5.

[51] O. A. Soria, A. C. Enríquez, L. T. Guajardo, Overcurrent relay with unconventional curves and its application in industrial power systems, Electric Power Systems Research 110 (2014) 113-121.

[52] A. C. Enriquez, E. Vazquez-Martinez, H. J. Altuve-Ferrer, Time overcurrent adaptive relay, International Journal of Electrical Power \& Energy Systems 25 (10) (2003) 841-847.

[53] A. Conde, E. Vázquez, Functional structure for performance improvement of time overcurrent relays, Electric Power Components and Systems 35 (3) (2007) 261-278. 
[54] S. Zocholl, J. Akamine, A. Hughes, M. Sachdev, L. Scharf, H. Smith, Computer representation of overcurrent relay characteristics: IEEE committee report, IEEE transactions on power Delivery 4 (3) (1989) 1659-1667.

[55] S. Jamali, H. Borhani-Bahabadi, Recloser time-current-voltage characteristic for fuse saving in distribution networks with DG, IET Generation, Transmission \& Distribution 11 (1) (2017) 272-279.

[56] S. Jamali, H.Borhani-Bahabadi, Non-communication protection method for meshed and radial distribution networks with synchronous-based DG, International Journal of Electrical Power \& Energy Systems 93 (2017) 468-478.

[57] S. Jamali, H. Borhani-Bahabadi, Self-adaptive relaying scheme of reclosers for fuse saving in distribution networks with DG, International Journal of Power and Energy Research 1 (1).

[58] A. Agrawal, M. Singh, M. Tejeswini, Voltage current based time inverse relay coordination for PV feed distribution systems, in: 2016 National Power Systems Conference (NPSC), IEEE, pp. 1-6.

[59] M. V. Tejeswini, B. C. Sujatha, Optimal protection coordination of voltage-current time based inverse relay for PV based distribution system, in: 2017 Second International Conference on Electrical, Computer and Communication Technologies (ICECCT), 2017, pp. 1-7. doi:10.1109/ICECCT.2017.8118006

[60] H. C. Kılıçkıran, H. Akdemir, İ. Şengör, B. Kekezoğlu, N. G. Paterakis, A non-standard characteristic based protection scheme for distribution networks, Energies 11 (5) (2018) 1241.

[61] M. Dewadasa, A. Ghosh, G. Ledwich, An inverse time admittance relay for fault detection in distribution networks containing DGs, in: TENCON 2009-2009 IEEE Region 10 Conference, IEEE, 2009, pp. 1-6.

[62] R. Majumder, M. Dewadasa, A. Ghosh, G. Ledwich, F. Zare, Control and protection of a microgrid connected to utility through back-to-back converters, Electric Power Systems Research 81 (7) (2011) 1424-1435.

[63] M. Dewadasa, R. Majumder, A. Ghosh, G. Ledwich, Control and protection of a microgrid with converter interfaced micro sources, in: ICPS'09. International Conference on Power Systems, IEEE, 2009, pp. 1-6.

[64] M. Dewadasa, A. Ghosh, G. Ledwich, Fold back current control and admittance protection scheme for a distribution network containing distributed generators, IET Generation, Transmission \& Distribution 4 (8) (2010) 952-962.

[65] A. Yazdaninejadi, D. Nazarpour, S. Golshannavaz, Dual-setting directional over-current relays: An optimal coordination in multiple source meshed distribution networks, International Journal of Electrical Power \& Energy Systems 86 (2017) $163-176$.

[66] D. S. Alkaran, M. R. Vatani, M. J. Sanjari, G. B. Gharehpetian, M. S. Naderi, Optimal overcurrent relay coordination in interconnected networks by using fuzzy-based GA method, IEEE Transactions on Smart Grid.

[67] C. A. C. Salazar, A. C. Enriquez, S. E. Schaeffer, Directional overcurrent relay coordination considering non-standardized time curves, Electric Power Systems Research 122 (2015) 42-49.

[68] C. Castillo, A. Conde, M. Shih, Improvement of non-standardized directional overcurrent relay coordination by invasive weed optimization, Electric Power Systems Research 157 (2018) 48-58.

[69] H. M. Sharaf, H. Zeineldin, D. K. Ibrahim, E. Essam, A proposed coordination strategy for meshed distribution systems with DG considering user-defined characteristics of directional inverse time overcurrent relays, International Journal of Electrical Power \& Energy Systems 65 (2015) 49-58.

[70] A. Chawla, B. R. Bhalja, B. K. Panigrahi, M. Singh, Gravitational search based algorithm for optimal coordination of directional overcurrent relays using user defined characteristic, Electric Power Components and Systems 46 (1) (2018) 43-55.

[71] H. M. Sharaf, H. Zeineldin, D. K. Ibrahim, E.-D. El-Zahab, Directional inverse time overcurrent relay for meshed distribution systems with distributed generation with additional continuous relay settings.

[72] M. Singh, Zone-2 setting of distance relays using user defined time-inverse over current relay charactieristics, in: Transmission and Distribution Conference and Exposition (T\&D), 2016 IEEE/PES, IEEE, 2016, pp. 1-5.

[73] M. Singh, V. Telukunta, S. Srivani, Enhanced real time coordination of distance and user defined over current relays, International Journal of Electrical Power \& Energy Systems 98 (2018) 430-441.

[74] A. YazdaniNejadi, S. Golshannavaz, D. Nazarpour, S. Teimourzadeh, F. Aminifar, Dual-setting directional overcurrent relays for protecting automated distribution networks, IEEE Transactions on Industrial Informatics.

[75] M. Shabani, A. Karimi, A robust approach for coordination of directional overcurrent relays in active radial and meshed distribution networks considering uncertainties, International Transactions on Electrical Energy Systems.

[76] A. Yazdaninejadi, J. Jannati, M. Farsadi, A new formulation for coordination of directional overcurrent relays in interconnected networks for better miscoordination suppression, Transactions on Electrical and Electronic Materials 18 (3) (2017) $169-175$.

[77] H. K. Karegar, et al., Relay curve selection approach for microgrid optimal protection, International Journal of Renewable Energy Research (IJRER) 7 (2) (2017) 636-642.

[78] J. K. Park, J. T. Kim, M.-C. Shin, A cordic-based digital protective relay and its architecture, Microelectronics Reliability 49 (4) (2009) 438-447. 
[79] A. M. Othman, A. Y. Abdelaziz, Enhanced backtracking search algorithm for optimal coordination of directional over-current relays including distributed generation, Electric Power Components and Systems 44 (3) (2016) 278-290.

[80] Z. Moravej, F. Adelnia, F. Abbasi, Optimal coordination of directional overcurrent relays using NSGA-II, Electric Power Systems Research 119 (2015) 228-236.

[81] F. Adelnia, Z. Moravej, M. Farzinfar, A new formulation for coordination of directional overcurrent relays in interconnected networks, International Transactions on Electrical Energy Systems 25 (1) (2015) 120-137.

[82] A. Azari, M. Akhbari, Optimal coordination of directional overcurrent relays in distribution systems based on network splitting, International Transactions on Electrical Energy Systems 25 (10) (2015) 2310-2324.

[83] M. Ezzeddine, R. Kaczmarek, A novel method for optimal coordination of directional overcurrent relays considering their available discrete settings and several operation characteristics, Electric Power Systems Research 81 (7) (2011) $1475-1481$.

[84] A. A. El-Fergany, H. M. Hasanien, Optimized settings of directional overcurrent relays in meshed power networks using stochastic fractal search algorithm, International Transactions on Electrical Energy Systems 27 (11).

[85] S. Ahmadi, H. Karami, M. Sanjari, H. Tarimoradi, G. Gharehpetian, Application of hyper-spherical search algorithm for optimal coordination of overcurrent relays considering different relay characteristics, International Journal of Electrical Power \& Energy Systems 83 (2016) 443-449.

[86] R. M. Chabanloo, H. A. Abyaneh, S. S. H. Kamangar, F. Razavi, Optimal combined overcurrent and distance relays coordination incorporating intelligent overcurrent relays characteristic selection, IEEE Transactions on Power Delivery 26 (3) (2011) $1381-1391$.

[87] D. L. Negrão, J. C. Vieira, The local fit method for coordinating directional overcurrent relays, IEEE Transactions on Power Delivery 31 (4) (2016) 1464-1472.

[88] A. A. Kida, L. A. Gallego, A high-performance hybrid algorithm to solve the optimal coordination of overcurrent relays in radial distribution networks considering several curve shapes, Electric Power Systems Research 140 (2016) 464-472.

[89] E. Sorrentino, Nontraditional relay curves for the coordination of the ground overcurrent function with downstream fuses, IEEE Transactions on Power Delivery 29 (3) (2014) 1284-1291.

[90] T. S. Aghdam, H. K. Karegar, H. Zeineldin, Optimal coordination of double-inverse overcurrent relays for stable operation of dgs, IEEE Transactions on Industrial Informatics.

[91] N. F. Sherbilla, T. A. Kawady, N. I. Elkalashy, A.-M. I. Taalab, Modified setting of overcurrent protection for distribution feeders with distributed generation, in: IET Conference on Renewable Power Generation (RPG 2011), IET, 2011, pp. 1-6.

[92] M. Khederzadeh, Back-up protection of distance relay second zone by directional overcurrent relays with combined curves, in: 2006 IEEE Power Engineering Society General Meeting, IEEE, pp. 6-pp.

[93] L. A. Kojovic, J. Witte, A new method in reducing the overcurrent protection response times at high fault currents to protect equipment from extended stress, in: 2001 IEEE/PES Transmission and Distribution Conf. and Exposition, Vol. 1, pp. 65-70.

[94] K. A. Saleh, H. H. Zeineldin, A. Al-Hinai, E. F. El-Saadany, Dual-setting characteristic for directional overcurrent relays considering multiple fault locations, IET Generation, Transmission \& Distribution 9 (12) (2015) 1332-1340.

[95] T. Keil, J. Jager, Advanced coordination method for overcurrent protection relays using nonstandard tripping characteristics, IEEE transactions on power delivery 23 (1) (2008) 52-57.

[96] M. Khederzadeh, Adaptive setting of protective relays in microgrids in grid-connected and autonomous operation, in: 11th IET International Conference on Developments in Power Systems Protection (DPSP), IET, 2012, p. page 14.

[97] E. Y. Erokhin, New overcurrent RST80 relays and their time-current characteristics, Russian E.E. 82 (3) (2011) $156-159$.

[98] M. S. Naderi, G. Gharehpetian, et al., Protection coordination of directional overcurrent relays: New time current characteristic and objective function, IET Generation, Transmission \& Distribution.

[99] J. Tan, P. McLaren, R. Jayasinghe, P. Wilson, Software model for inverse time overcurrent relays incorporating IEC and IEEE standard curves, in: Canadian Conference on Electrical and Computer Engineering. IEEE CCECE 2002., Vol. 1, pp. 37-41.

[100] V. Calderaro, V. Galdi, A. Piccolo, P. Siano, Adaptive relays for overhead line protection, Electric Power Systems Research 77 (12) (2007) 1552-1559.

[101] M. Ojaghi, R. Ghahremani, Piece-wise linear characteristic for coordinating numerical overcurrent relays, IEEE Transactions on Power Delivery 32 (1) (2017) 145-151.

[102] M. Lwin, J. Guo, N. Dimitrov, S. Santoso, Stochastic optimization for discrete overcurrent relay tripping characteristics and coordination, IEEE Transactions on Smart Grid PP (99) (2017) 1-1. doi:10.1109/TSG.2017.2751596 